\title{
Carneous mole in a depressed patient: a diagnostic dilemma
}

\author{
Nisha Bhagat ${ }^{1 *}$, Rajnish Raj $^{2}$ \\ ${ }^{1}$ Department of Obstetrics and Gynecology, ${ }^{2}$ Department of Psychiatry, Government Medical College, Patiala, Punjab, \\ India
}

Received: 22 May 2017

Accepted: 20 June 2017

\section{*Correspondence:}

Dr. Nisha Bhagat,

E-mail: nishabhagat07@yahoo.com

Copyright: ( ) the author(s), publisher and licensee Medip Academy. This is an open-access article distributed under the terms of the Creative Commons Attribution Non-Commercial License, which permits unrestricted non-commercial use, distribution, and reproduction in any medium, provided the original work is properly cited.

\begin{abstract}
Carneous mole is a pathological variant of missed abortion of a fetus less than 12 weeks. It's medically managed by giving repeated doses of misoprostol with or without dilatation and curettage. Due to ambiguity in diagnosis and misleading clinical examination and investigations, surgical exploration was considered as the best approach. The case of carneous mole with depression is reported because of its rarity; as in this case, ammenorrhea was the only presenting complaint and all other laboratory tests, investigations and radiological report failed to detect carneous mole, which was diagnosed incidentally on exploratory laparotomy.
\end{abstract}

Keywords: Carneous mole, Depression, Selective serotonin reuptake inhibitor

\section{INTRODUCTION}

The mental health of the mother influences foetal wellbeing. A normal outcome of pregnancy can never be guaranteed. Depression during pregnancy has been associated with numerous adverse obstetrical outcomes, including poor maternal weight gain and greater risk of preeclampsia, preterm delivery. ${ }^{1}$ It is unclear if depression increases the risk of spontaneous abortion, having a low birth weight or small for gestational age. The spontaneous abortion rate in confirmed early pregnancy is $10-20 \%$ and risk of malformation is $2-3 \%{ }^{2}$ The use of antidepressants are common during pregnancy or prior to pregnancy in case of established major depressive disorder. The majority of prescriptions are for selective serotonin receptor inhibitors (SSRIs). ${ }^{3}$ Tricyclic antidepressants (TCAs) are also widely used throughout pregnancy without apparent detriment to the foetus. ${ }^{4}$ SSRIs have been associated with spontaneous abortion..$^{5,6}$ Most of the women stops taking antidepressants $(<6$ weeks of gestation) because of concerns about teratogenicity. ${ }^{7}$ It has been suggested that SSRIs may cause irregular uterine bleeding by reducing serotonin- mediated uterine contraction as well as interfering with hemostasis. ${ }^{8}$

Carneous mole is also known as tuberose mole, blood mole and breus mole. This is caused by small repeated hemorrhages in choriodecidual space that do not rupture the decidua capsularis but disrupts villi from its attachment thus, forming a mass of clotted blood inside a dead or rudimentary ovum. ${ }^{9}$ Ten placentae with massive sub-chorionic thrombo-haematomas were reported in literature. Their lesions were composed of maternal clotted blood that separates chorionic plate of placenta from villous chorion and traversed the main cotyledon branches of foetal circulation. ${ }^{10}$ Occasionally, the patient complaints of ammenorrhea and had typical signs and symptoms of pregnancy or passage of brown or dark colored vaginal discharge. If, carneous mole is retained for longer duration, all signs and symptoms of pregnancy regresses and even biochemical tests i.e., urinary pregnancy test (UPT) become negative.

We report a case of recurrent depression that was treated with SSRIs but unlikely to have association with 
carneous mole, which was detected incidentally on laparotomy.

\section{CASE REPORT}

A 32-year old female, P2 L2 A1 of North India, reported to outdoor patient department of Psychiatry Government Medical College and Rajindra Hospital, Patiala and was a known case of recurrent depressive disorder on treatment with antidepressant Fluoxetine $20 \mathrm{mg}$ per day but reported with chief complaints of sadness of mood, loss of appetite, lethargy, insomnia for the last 5 months and suicidal ideation for the last 2 weeks. There had been previous two episodes of depression with inter-episodic full remission and recovery. There was no history of any psychiatric illness in family, substance use disorder, any other psychiatric or organic mental disorder.

She had history of ammenorrhea and pain in the lower abdomen for last 4 months; and something coming out of vagina with heaviness in perineum for the last 7 years. Hence, obstetrics and gynecology consultation was sought, which revealed pain in the hypogastric region, mild in intensity, radiating to back, without any diurnal or postural relation but had difficulty in passing urine. She has two children, elder 12 year old female and younger 9 year old male; both were born via normal vaginal delivery. Two years ago, she underwent surgical evacuation due to missed abortion at 8 weeks. After her abortion, she used to have an irregular menstrual cycle, which lasted for 35-60 days with mild lower abdomen pain of 3-4 days. Earlier her menstrual history was normal. The couple occasionally used condom method for contraception. There was no history of loss of appetite or weight gain, galactorrhoea, hirsutism, hot flushes, chronic illness e.g., thyroid, diabetes, tuberculosis, epilepsy etc., or any chronic drug intake. There was no other significant family or surgical history.

On general physical examination, patient was conscious, well oriented to time, place and person, moderately built and nourished. Her vitals were within normal limits i.e., blood pressure $126 / 82 \mathrm{~mm}$ of $\mathrm{Hg}$, pulse rate $76 / \mathrm{min}$, regular in rate, rhythm and volume and respiratory rate 16/min; no pallor was present. Abdomen was soft and non-tender, no mass was palpated, no rigidity felt. Vaginal examination revealed backward directed cervix, 6 weeks sized anteverted uterus, and a cystic mass was felt through left fornix, about $2 \times 3 \mathrm{~cm}$, non-tender, slightly mobile and separated from uterus. Right fornix was clear and non-tender. There was second degree of cervical descent with a minimal cystocele and rectocele. UPT was negative. All hematological parameters and thyroid profile were within normal limits. Ultrasonogram (USG) of pelvis revealed anteverted uterus with moderate fluid in endometrial cavity having thick and thin internal septations of chronic hematometra. Two masses were seen in the left adnexa measuring $2 \times 2 \mathrm{~cm}$ and $2.5 \times 2 \mathrm{~cm}$ with fine septations and separately defined from left ovary. CA-125 level was normal. Computer tomogram
(CT) of pelvis showed intensely vascular uterine cavity suggestive of arterio-venous (A-V) shunting could be A$\mathrm{V}$ malformation or vascular neoplasm of $5 \times 6 \mathrm{~cm}$ size with a fibroid of $2.5 \times 3 \mathrm{~cm}$ on the posterior wall of the uterus. Hysteroscopic examination was inconclusive. Any of the following differential diagnosis of Tubo-ovarian (TO) mass, vascular neoplasm or degenerated fibroid was expected, thus an exploratory laparotomy was planned.

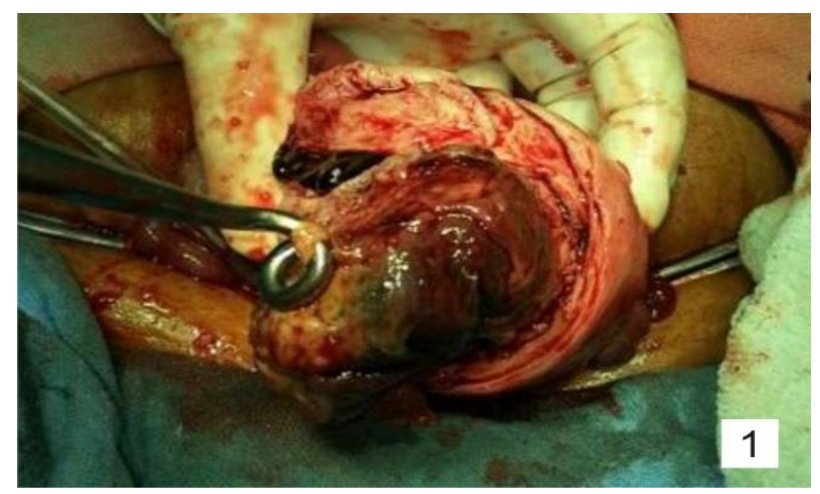

Figure 1: The mass of $5 \times 7 \mathrm{~cm}$ attached to anterior uterine wall.

Operative laparotomy findings showed uterus of 6 weeks size with degenerated fibroid of $2 \times 3 \mathrm{~cm}$ on posterior surface of uterus (intramural becoming sub-serosal) with central softening. On opening uterine cavity, a wellorganized soft mass of $5 \times 7 \mathrm{~cm}$ was attached to anterior uterine wall and fundus (Figure 1). Cut-section of the organized mass revealed a small embryo of $10 \mathrm{~mm}$ (Figure 2). Abdomen was closed in layers and Manchester operation was done to give the patient a better quality of life. Histopathologically, the report of the patient revealed chorionic villi, deciduas and blood clots that confirmed the diagnosis of carneous mole. The patient recovered well and was discharged on $8^{\text {th }}$ postoperative day.

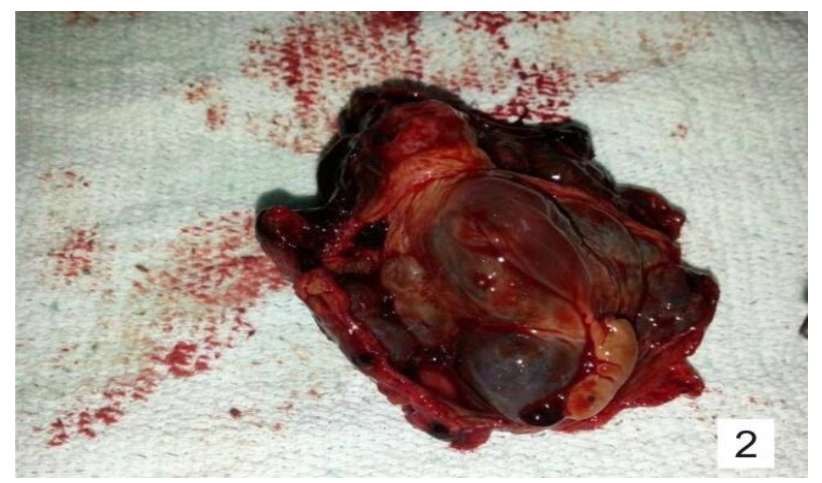

Figure 2: Cut-section of mass revealed embryo (arrow) of $10 \mathrm{~mm}$ sized.

A diagnosis of depression was made on semi-structured Diagnostic and Statistical Manual of Mental Disorder (DSM-5), which revealed a clinical diagnosis of 296.32 (F33.11) i.e., Recurrent Major depressive disorder 
(MDD) with specifier: moderate, with somatic syndrome. The severity was assessed on Beck Depressive Inventory (BDI) scale and Patient Health Questionnaire (PHQ-9) whereas suicidal ideation during the past two weeks on Beck Suicidal Ideation (BSI) scale; and Clinical outcome on Clinical Global Impression-Severity (CGI-S) Scale which revealed the scores of 24, 21, 14 and 4 respectively, indicating that depression was of moderate intensity and required treatment. ${ }^{11-15}$

Patient was given psycho-education, crisis-intervention psychotherapy and pharmacotherapy with Fluoxetine 20 mg per day, which was gradually titrated to the therapeutic level of $60 \mathrm{mg}$ per day and Clonazepam 0.5 $\mathrm{mg}$ at night for fifteen days that was later on tapered-off. Hence, it was important to make treatment plan, consider counselling, follow-up, and/or prescription drugs. Clinicians used the PHQ-9 to evaluate treatment response and periodically, two weeks follow-up for 12 weeks. At the $12^{\text {th }}$ week her BDI, PHQ-9, BSI, Clinical Global Impression- Improvement Scale (CGI-I) scores were 6, 5, 5 and 1 that indicated depression to be in full remission. WHO-UMC causality scale showed that this phenomenon (carneous mole) was unlikely to the drug (SSRIs) and made its relationship improbable (but not impossible) or otherwise carneous mole provided the independent plausible explanation for the diagnosis. Furthermore, Naranjo's adverse drug reaction probability scale also showed a score of 0 , indicating no association. ${ }^{16,17}$

\section{DISCUSSION}

The tuberose or carneous mole is the most striking form of abortion, and second in interest and importance to hydatidiform mole. The most common form of carneous mole is a thickened fleshy looking structure averaging $6 \times 6 \mathrm{~cm}$ in diameter and $1.5 \mathrm{~cm}$ in thickness. ${ }^{18}$

Diagnosis is made by general physical examination, per abdomen examination and pelvic examination and supported by laboratory investigations including UPT and imaging studies. USG is mandatory for making diagnosis which may show empty gestational sac in early pregnancy or absence of fetal cardiac activity in later pregnancy. Surgical evacuation using suction curettage is the standard treatment of missed abortion in first trimester. Expectant and medical management are other alternatives, but should be offered only in places where facilities of emergency evacuation are available. About $50 \%$ women with anembryonic pregnancy and 35\% with missed abortion will abort completely within 14 days, when followed expectantly. ${ }^{19}$

Misoprostol and mifepristone have both been used successfully for medical management of missed abortion. The most common regimens use 400-600 $\mu \mathrm{g}$ of vaginal misoprostol in single or multiple doses with success rate of $70-80 \%$. Oral misoprostol is also effective although the time taken for expulsion of products is longer than with vaginal route. ${ }^{20}$ Misoprostol has also been used sublingually, but the incidence of adverse effects like pain, diarrhea and fever are greater. ${ }^{21}$ Mifepristone has been used alone or in combination with misoprostol. However, multi-centric trial showed that pretreatment with mifepristone did not increase the success rate. The two factors that are associated with increased chances of success with medical management are increased serum $\beta$ hCG levels of 2000-20,000 IU/L; and gestational period of less than 75 days. $^{22}$

In the present case, there was ambiguity in diagnosis (the only symptom in favor of pregnancy was ammenorrhea of four and half months) due to conflicting findings of UPT, USG and CT scan pelvis. Thus, an exploratory laparotomy was considered to be the best approach in ascertaining its diagnostic validity and management. Our management approach was in consonance with Stevens's who performed exploratory laparotomy for retained carneous mole in utero for 15 months. ${ }^{23}$

The symptoms of depression occurred prior to the medical illness of carneous mole. There was history of psychiatric illness in the past where the first episode occurred 5 years ago, then after 3 years and current episode of 5 months with worsening of mood and suicidal ideation but had no psychiatric illness in her family of first or second-degree relatives. It could not be attributed to a normative stress reaction to complication of failed pregnancy or dysfunctional array of hypothalamicpituitary-adrenal axis (HPA) or any other substance/drugs use etc.

Approximately $10 \%$ of pregnant women develop depressive illness and further $16 \%$ self-limiting depressive reaction. ${ }^{24}$ There is significant increase in new psychiatric episodes in the first 3 months after delivery and $80 \%$ are depressive disorders. The causality assessment for association of SSRIs induced carneous mole was unlikely on WHO-UMC scale and Naranjo's scale.

\section{CONCLUSION}

Carneous mole can be misleading at times, especially, if it is retained for more than 12 weeks and without any complications. Laboratory investigations e.g., UPT and CT imaging etc. are of not much help. Clinicians should have a high level of suspicion to detect such an entity in early stage of illness and thus, avoid unnecessary surgical intervention and mental trauma. It is possible that carneous mole is primarily associated with the maternal depression rather than use of antidepressant SSRIs, which needs further studies. Thus, the best treatment from the outset is critical and the ideal medication balances safety, efficacy and preconception planning for Maternal and Child Health Care.

\section{Funding: No funding sources Conflict of interest: None declared Ethical approval: Not required}




\section{REFERENCES}

1. Marcus SM. Depression during pregnancy: rates, risks and consequences-mother risk update 2008. Canadian J Clin Pharm. 2009;16(1):e15-e22.

2. McElhatton PR. Pregnancy: General principles of drug use in pregnancy. Pharm J. 2003;270:232-4.

3. Riggin L, Frankel Z, Moretti M, Pupco A, Koren G. The fetal safety of fluoxetine: a systemic review and meta-analysis. J Obstet Gynaecol Can. 2013;35:3629.

4. Gentile S. Tricyclic antidepressants in pregnancy and peurperium. Expert Opin Drug Saf. 2014;13:207-25.

5. Hemels ME, Einarson A, Koren G, Lanctot KL, Einarson TR. Antidepressant use during pregnancy and the rates of spontaneous abortion: a metaanalysis. Ann Pharmacother. 2005;39:803-9.

6. Nakhai-Pour HR, Broy P, Berard A. Use of antidepressants during pregnancy and the risk of spontaneous abortion. CMAJ: Canadian Medical Association Journal. 2010;182(10):1031-7.

7. Petersen I, Gilbert RE, Evans SJ, Man SL, Nazareth I. Pregnancy as a major determinant for discontinuation of antidepressants: an analysis of data from the Health Improvement Network. J Clin Psychiatry. 2011;72:979-85.

8. Lupattelli A, Spigset O, Koren G, Nordeng H. Risk of vaginal bleeding and postpartum hemorrhage after use of antidepressants in pregnancy: a study from the Norwegian Mother and Child Cohort Study. J Clin Psychopharmacol. 2014;34:143-8.

9. Dutta DC. DC Dutta's Textbook of Obstetrics, Hiralal Konar (editor).7th ed. Kolkata: New Centre Book Agency Pvt Ltd;2011:163-4.

10. Shanklin D R and Scott J S. Massive subchorial thrombohaematoma (BREUS' MOLE). BJOG: Int J Obstet Gynaecol. 1975;82:476-87.

11. American Psychiatric Association. Diagnostic and Statistical manual of mental disorders (DSM-5), 5th ed. Arlington, VA: American Psychiatric Association. Washington DC;2013.

12. Beck AT, Ward CH, Mendelson M, Mock J and Erbaugh J. An inventory for measuring depression. Arch Gen Psychiatry. 1961;4:561-71.

13. Kroenke K, Spitzer RL. The PHQ-9: A New Depression Diagnostic and Severity Measure. Psychiatr Annals. 2002;32:1-7.
14. Beck AT, Kovacs M and Weissman A. Assessment of suicide intention: The scale ideation. J Consul Clin Psychol.1979;47:343-52.

15. Beneke M, Rasmus W. Clinical global impressions (ECDEU): some critical comments. Pharmacopsychiatry.1992;25:171-6.

16. The use of the WHO-UMC system for standardized case causality assessment. Available at http//:www.who-umc.org/Graphics/24734.pdf Accessed on 20th May 2017.

17. Naranjo CA, Busto U, Sellers EM, Sander P, Ruiz I, Roberts EA et al. A method for estimating the probability of adverse drug reactions. Clin Pharmacol Ther. 1981;30:239-45.

18. Hart DB. The nature of the tuberose fleshy mole. BJOG: Int J Obstet Gynaecol. 1902;1:479-87.

19. Casikar I, Bignardi T, Riemke J, Alhamdan D, Condous G. Expectant management of spontaneous first -trimester miscarriage: Prospective validation of the '2-week rule'. Ultrasound Obstet Gynecol. 2010;35(2):223-7.

20. Ngoc NT, Blum J, Westheimer E, Quan TT, Winikoff B. Medical treatment of missed abortion using misoprostol. Int $\mathbf{J}$ Gynecol Obstet. 2004;87(2):138-42.

21. Tanha FD, Feizi M, Shariat M. Sublingual versus vaginal misoprostol for the management of missed abortion. J Obstet Gynecol Res. 2010;36(3):525-32.

22. Gronlund A, Gronlund L, Clevin L, Andersen B, Palmgren N, Lideegard Q. Management of missed abortion: comparison of medical treatment with either mifepristone + misoprostol or misoprostol alone with surgical evacuation. A multi-center trial in Copenhagen Country, Denmark. Acta Obstet Gynecol Scand. 2002;81(11):1060-5.

23. Stevens TG. Carneous Mole Retained Fifteen Months in Utero. Proceed Royal Soci Medicine. 1926;19:43.

24. Yonkers KA, Wisner KL, Stewart DE, et al. The management of depression during pregnancy: a report from the American Psychiatric Association and the American College of Obstetricians and Gynaecologists. Gen Hosp Psychiatry. 2009;31(5):403-13.

Cite this article as: Bhagat N, Raj R. Carneous mole in a depressed patient: a diagnostic dilemma. Int $\mathbf{J}$ Reprod Contracept Obstet Gynecol 2017;6:3685-8. 